\title{
CONTROL DE BACTERIOSIS EN EL CULTIVO DE MELÓN
}

\author{
${ }^{\bullet}$ Felipe Rafael Garcés Fiallos ${ }^{1}$ y Erlei Melo Reis ${ }^{2}$ \\ ${ }^{1}$ Unidad de Investigación Cientifica y Tecnológica, Universidad Técnica Estatal de Quevedo, $\mathrm{km} 1$ 112 vía \\ Quevedo-Santo Domingo de los Tsáchilas, C. P. 73. Quevedo, Los Ríos, Ecuador. ${ }^{\circ}$ felipegarces23@yahoo.com \\ ${ }^{2}$ Facultad de Agronomía e Medicina Veterinaria, Universidad de Passo Fundo, \\ Caja postal 611, 99001-970, Passo Fundo, Río Grande del Sur, Brasil
}

\begin{abstract}
RESUMEN
$\mathrm{D}$ entro de las enfermedades bacterianas que ataca al cultivo de melón a nivel mundial, se encuentran varias bacteriosis, en donde la más importante es la mancha bacteriana de los frutos o mancha acuosa, causada por Acidovorax avenae subsp. citrulli. Los daños pueden llegar hasta $100 \%$ de daños cuando las condiciones son ideales para el patógeno. Los síntomas de esta enfermedad son fácilmente observados en los frutos y no existe todavía medidas de control bien establecidas para su control. A pesar de eso, en esta revisión se ha tratado de colocar lo más relevante e importante en relación a la fitobacteria, incluyendo las medidas de control más utilizadas en el cultivo de melón.
\end{abstract}

Palabras claves: Cucumis melo, Acidovorax avenae subsp. citrulli, estrategias de control/manejo integrado.

\begin{abstract}
mong the bacterial born diseases there are several that affect melon crop worldwide, being the bacterial spot of the fruits or aqueous stain, caused by Acidovorax avenae subsp. citrulli the most important. The losses may reach $100 \%$ damage when environmental conditions are ideal for the development of the pathogen. The symptoms of this disease are easily observed in the fruits and there is not a well established measure for their control yet. Despite that the most relevant and important information available and related to this fitobacteria, including the control measures more used in the melon production are reviewed.
\end{abstract}

Key words: Cucumis melo, Acidovorax avenae subsp. citrulli, strategies of control/management integrated.

\section{INTRODUCCIÓN}

$\mathrm{E}_{\mathrm{l}}^{1}$ cultivo de melón (Cucumis melo L.), es una de las hortalizas más cultivadas en el mundo. Dentro de los países exportadores a nivel mundial, Brasil es el quinto exportador, cuyas exportaciones alcanzaron las $142,590.00 \mathrm{TM}$ (16\% de las exportaciones mundiales) en el 2004, teniendo así un ingreso para el país de USD 63’250,000.00.

Dentro de las 14 especies frutículas contempladas por el Programa de Producción Integrada de Frutas (PIF) está el melón (Cucumis melo L.), en función de su gran contribución en la balanza comercial de frutas frescas (Andrigueto y Kososki, 2003).

Dentro de las enfermedades causantes de bacteriosis en el cultivo de melón, están las manchas bacterianas del fruto causadas por Acidovorax avenae subsp. citrulli, "barriga de agua" causada por Xanthomonas campestris pv. melonis y pudrición blanda de los frutos causada por Erwinia carotovora subsp. carotovora (Pinto et al., 2002). Infelizmente no existen investigaciones en todas las bacteriosis en melón, existiendo en su mayoría trabajos con la mancha bacteriana del fruto causada por $A$. avenae subsp. citrulli.

Recibido: Mayo, 2009. Aceptado: Julio, 2009.

Publicado como ARTICULO REVISION en Ciencia y Tecnología 2(2): 1-6. 2009

\section{Mancha bacteriana del fruto o acuosa causada por Acidovorax avenae subsp. citrulli.}

$\mathrm{L}$ a mancha acuosa causada por $A$. avenae subsp. citrulli. fue reportada por primera vez en las Islas Mariana, Estados Unidos en el año 1988 infectando sandía (Citrullus lanatus) (Wall y Santos, 1988). Posteriormente, apareció una grave epidemia en todo el este de Estados Unidos en 1994, donde miles de hectáreas de sandía en al menos 10 Estados se vieron afectados (Hopkins et al., 1996). En melón, el primer relato de esta enfermedad fue realizada en Estados Unidos en 1996, mostrando una incidencia mayor a 50\% de frutos infectados en campos agrícolas en el Estado de Texas (Isakeit et al., 1997). Después, la fitobacteria $A$. avenae subsp. citrulli, fue relatada inicialmente en Brasil infectando melón, causando la mancha bacteriana de los frutos o mancha acuosa (Robbs et al., 1992). Se cree que esta bacteria fue introducida en Brasil a través de semillas contaminadas (Asiss et al., 1999). Para esta bacteria, la remoción, el transporte para otras plantas o plantaciones y la deposición, son favorecidos por las salpicaduras de lluvia. Maude (1996) denomina esos propágulos de esporas húmedas, teniendo así una diseminación pasiva.

Semillas contaminadas, plántulas infectadas y 
restos culturales, constituyen en las principales fuentes de inóculo de esta bacteria (Hopkins et al., 1996). La diseminación del inóculo a larga distancia, ocurre principalmente por semillas contaminadas. Después de la germinación, la bacteria es fácilmente diseminada para plántulas/plantas vecinas a través de salpicaduras de agua lluvia, irrigación por aspersión y prácticas culturales. Zitter et al. (1996) menciona este patógeno que para ocurrir la infección se precisa de 30 minutos de mojado y temperaturas alrededor de $26^{\circ} \mathrm{C}$. Michereff y Barros (2001) indica que las lesiones en las hojas de las plantas son una importante fuente de inóculo para los frutos, que a su vez, cuando están maduros sirven como inócu- lo para el próximo plantío. El mismo autor relata que la penetración de la bacteria ocurre tanto en la hoja como en el fruto a través de aberturas naturales y/o heridas.

Los síntomas de la mancha acuosa, se manifiestan por la aparición de lesiones necróticas en el margen de la hoja y creciendo hacia el interior del nervio medio (Walcott et al., 2000). En los frutos maduros antes de la cosecha, donde los síntomas son más visibles, la cáscara presenta manchas acuosas con o sin la presencia del halo e internamente, la pulpa se presenta marrón - amarillento, alcanzando las semillas que pueden ser contaminadas externamente e internamente (Silva et al., 2006).

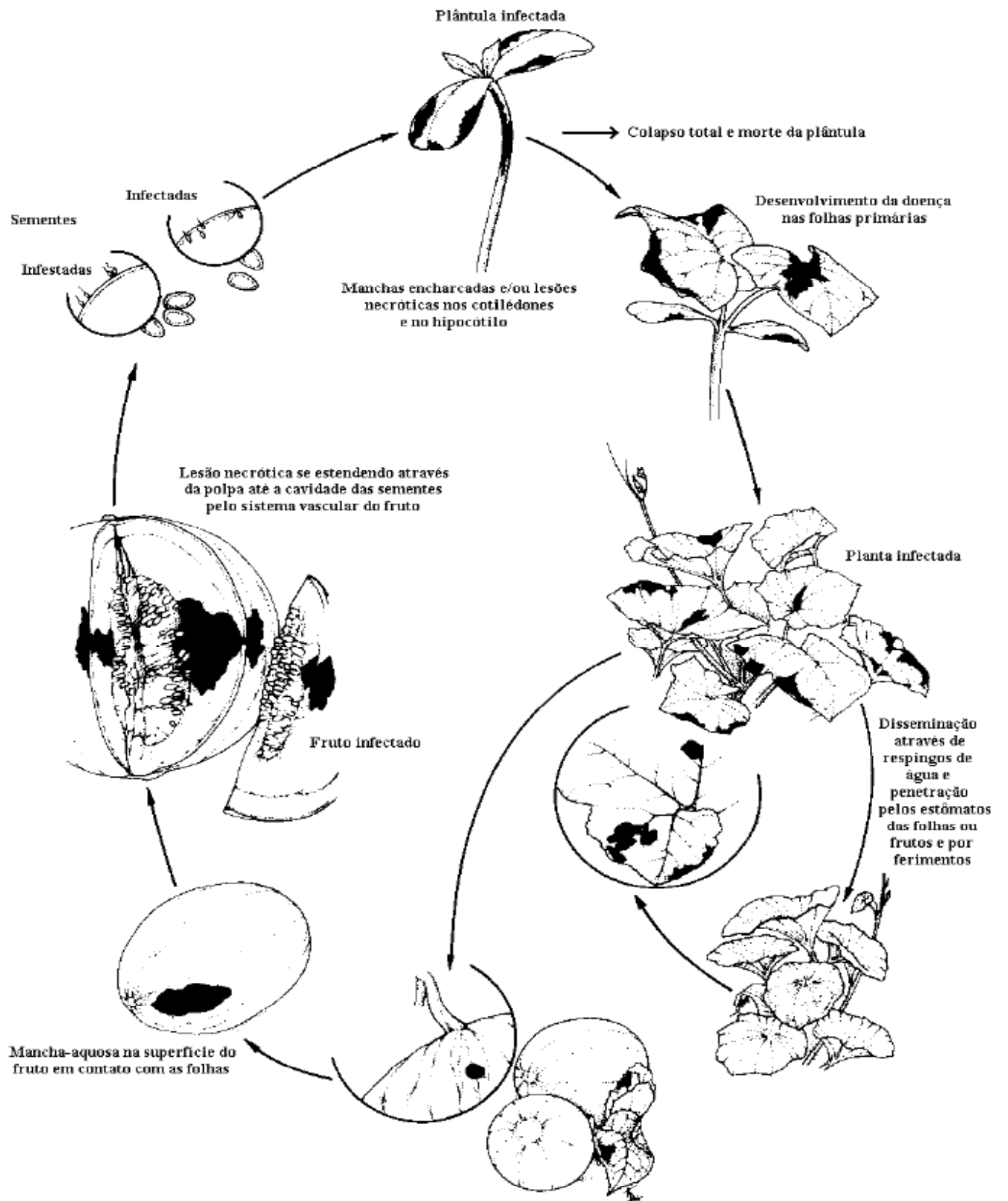

Figura 1. Ciclo de la mancha acuosa causada por Acidovorax avenae subsp. citrulli en melón (Mariano et al., 2001). 
Oliveira et al. (2003), relata que esta enfermedad ha alcanzado proporciones endémicas en plantaciones de melón en los Estados de Río Grande del Norte $(\mathrm{RN})$ y Ceará (CE), mayores productores del Noroeste y de Brasil, causando frecuentemente 40 a $50 \%$ de daño, mientras que Sales y Menezes (2001) mencionan que puede alcanzar hasta un $100 \%$ de daños. El melónpepino (Cucumis melo var. cantalupensis Naud) es una cucurbitácea cultivada en RN para consumo doméstico, donde frutos de melón-pepino, con síntomas semejantes a los de mancha acuosa, provenientes del Municipio de Baraúna, RN, fueron colectados en un supermercado de Mossoró, RN, encontrando en la superficie de los frutos lesiones por causa de esta enfermedad entre $5 \mathrm{y}$ $10 \mathrm{~mm}$ de diámetro (Oliveira et al., 2003).

La severidad de la mancha acuosa aumenta en función de la concentración de inóculo, resaltando la importancia del control de esta bacteria en las fuentes de inóculo hacia las infecciones en las hojas, tales como hospederos voluntarios, hospederos alternativos y semillas, también las hojas de la planta de melón infectadas sirven como reservorio de la bacteria para la infección de frutos y los restos culturales (Isakeit et al., 1997).

La bacteria puede diseminarse rápidamente, siendo así, que pocos sitios de la infección primaria pueden resultar en $100 \%$ de infección en los frutos en la época de la cosecha (Hopkings et al., 1992). En Rio Grande del Norte la irrigación por goteo es un factor que no favorece el mojado foliar siendo, una práctica recomendable en el manejo de la enfermedad (Silveira et al., 2004).

En un trabajo realizado por Araújo et al., (2005), demostraron que $A$. avenae subsp. citrulli es capaz de penetrar en frutos de sandía íntegros por aberturas naturales (estomas), más con la maduración del fruto esta penetración es dificultada por la barrera morfológica producida por la cera que llega a cubrir 66 a $73 \%$ de los estomas, cinco semanas después de la antesis.

Según Nascimento et al., (2004), en una investigación realizada utilizando dos cepas de $A$. avenae subsp. citrull (Aac 1.49 y Aac 12.13), manifiesta que con relación a la gama de hospederos, esta bacteria Aac, aparte de causar mancha acuosa en melón cvs. Pele de Sapo, São Caetano, melón-pepino y sandía (Citrullus lanatus L.) cv. Charleston Gray, también pueden causar mancha acuosa en zapallo (Cucurbita maxima Duchesne) cv. Menina creme, calabacín (Cucurbita pepo L.) cv. Menina brasileira, pimiento (Capsicum annum L.) cv. All big, maxixe (Cucumis anguria L.) cv. Del Norte, pepino (Cucumis sativus L) cv. SMR 58, tomate (Lycopersicon esculentum Mill.) cv. Santa clara, calabaza moranga (Cucurbita maxima Duchesne) cv. Exposição, en berenjena (Solanum melongena L.) cv. Comprida roxa y en papaya (Carica papaya L.) cv. Sunrise solo, mostrando valores de incidencia de mancha acuosa desde $34.37 \%$ hasta $100 \%$.

\section{Estrategias de Control/Manejo Integrado}

$A_{\text {por muchos investigadores en diferentes trabajos. }}^{\text {continuación se enumera los controles utilizados, }}$

\section{Control cultural}

El control cultural trata básicamente evitar la entrada del patógeno en el área y, cuando ya esté presente, impedir que encuentre las condiciones favorables de infección, multiplicación y diseminación. Dentro de las medidas culturales más eficientes para eliminar o reducir los efectos de las enfermedades bacterianas en plantas, destacan: Preferir cultivares resistentes, cuando hubieran disponibles; usar material propagativo de procedencia conocida; evitar plantar en época no favorable a la enfermedad; plantar en terrenos con historial de ocurrencia de enfermedades asociadas al suelo: realizar una fertilización basada en un análisis de suelo; usar un espaciamiento que permita buena ventilación de las plantas; evitar áreas sujetas al encharcamiento; irrigar con agua de buena calidad y en cantidad adecuada (riego por goteo); realizar rotación de cultivos y evitar o proteger los sitios de penetración del patógeno, que son heridas causadas por insectos, vientos, podas, desbrotes y deshierbas (Lopes, 2001).

La comprobación de la habilidad de esta bacteria para sobrevivir epifiticamente en un mínimo de 60 días en la raíces y en la rizósfera de la planta de melón, refuerza la importancia de aplicación de algunas medidas de control, tales como: erradicar plantas voluntarias, destruir restos de cultivos, principalmente en campos con plantas infectadas, eliminar otras hospederas alternativas, en las cuales la bacteria, probablemente, también sobrevive en el rizoplano y rizósfera, aparte del filoplano (Silva et al., 2006).

Una de las principales medidas de control recomendadas para la mancha acuosa, es que después de la introducción de la enfermedad en el campo, realizar rotación de cultivo con plantas no hospederas de otras familias botánicas, por lo menos durante 1 a 2 años (Walcott et al., 2001).

Morrison (1999), menciona que es importante evaluar semillas sanas ya que es un instrumento de gestión esencial para el control de transmisión de enfermedades y patógenos por las semillas, además de que sigue siendo una actividad importante para su regulación y control, a través de medidas fitosanitarias y cuarentena en los programas de comercio nacionales e internacionales de semillas. 


\section{Control biológico}

La mancha acuosa, causada por A. avenae subsp. citrulli (Aac) causa grandes perjuicios al cultivo de melón. El control de esa enfermedad se estudió en vivo, con micronebulización de semillas de melón Amarelo infectadas, con líquidos fermentados de $\mathrm{Baci}$ llus subtilis R14, B. megaterium pv. cerealis RAB7, $B$. pumilus $\mathrm{C} 116$ e Bacillus sp. MEN2, con y sin células bacterianas. Los resultados fueron los siguientes: $B$. megaterium pv. cerealis RAB7 proporcionó reducción de la incidencia $(89.1 \%$ ) y del índice de la enfermedad (92.7\%), elevó el período de incubación de la mancha acuosa de 9.8 para 11.9 días y disminuyó la ABCPE (Área bajo la curva de progreso de la enfermedad) de 3.36 para 0.17 . In vitro, todos los aislados presentaron antibiosis contra Aac y los compuestos bioactivos fueron parcialmente caracterizados como lipopéptidos. De esta forma, se sugiere que el control de la mancha acuosa en plántulas de melón por el tratamiento de semillas sea debido a los compuestos lipopeptídicos producidos por las especies de Bacillus evaluadas (Santos et al., 2006).

\section{Control genético}

Cuando las condiciones encontradas en la región son favorables para el desarrollo de la enfermedad, el sembrío de cultivares susceptibles puede resultar en perjuicios económicos. La utilización de cultivares Pele de Sapo y Português, resistentes a la bacteria en este estudio, se torna una alternativa de control de la enfermedad (Assis et al., 1999). No existen otras referencias sobre resistencia a mancha acuosa en cultivares de melón (Silva et al., 2003).

\section{Control químico}

El control de fitobacterias ha sido blanco de constantes críticas, pues su eficiencia, a través de la aplicación de antibióticos o de fungicidas cúpricos, es errática. Resultados sobre la ausencia del control no son publicados. Entretanto, la literatura muestra que el control químico es apenas razonable y solamente funciona sobre condiciones poco favorables a la ocurrencia de la enfermedad. Fungicidas a base de cobre, en las formulaciones hidróxido de cobre, oxicloruro de cobre, sulfato de cobre y oxido cuproso, han sido ampliamente recomendados para el control de enfermedades bacterianas, con registro para un gran número de cultivos (Lopes, 2001).

Bezerra (2002), menciona que es importante recordar que para el éxito de un método de control químico eficiente con bactericidas, existen algunos factores a ser tomados en consideración, tales como el momento de aplicación, inicio de los síntomas en hojas, modo de aplicación, utilización de equipamientos regulados periódicamente, tomando en consideración el volumen de caldo aplicado, presión de las boquillas, etc.

Hopkings et al., (2003) indican que el ácido peroxiacético (AP) puede ser usado para controlar la transmisión de las semillas con mancha acuosa producida por A. avenae subsp. citrulli y de otras enfermedades transmitidas por las semillas en cucurbitáceas. Un tratamiento efectivo de semillas mojadas en su protocolo, incluyó un tratamiento de 30 minutos de AP en 1600 $\mu \mathrm{g} / \mathrm{mL}^{-1}$, seguidamente las semillas son secadas a baja humedad en una estufa a $40{ }^{\circ} \mathrm{C}$ por $48 \mathrm{~h}$. El AP podría tornarse una herramienta importante en contrarrestar las enfermedades transmitidas por las semillas en cucurbitáceas, especialmente en mancha acuosa.

La eficiencia en cuanto a la reducción de la incidencia de la enfermedad de la mancha acuosa en melón, obtenida por casugamicina (70 ppm) y por oxicloruro de cobre (1250 ppm), fueron observadas separadamente en Mossoró, en condiciones desfavorables a la enfermedad, no habiendo sinergismo entre los dos tratamientos. Ya en Icapuí, sobre condiciones favorables a la enfermedad, fue observada la eficiencia para la mezcla casugamicina + oxicloruro de cobre $(40+1250 \mathrm{ppm})$ y para oxitetraciclina $(82 \mathrm{ppm})$. Siendo así, según los datos obtenidos en ese trabajo realizado in vitro, los dos ensayos de campo demostró que el activo casugamicina se presenta como una excelente alternativa para el control de $A$. avenae subsp. citrulli. Principalmente cuando la misma fuera alternada con aplicaciones de oxicloruro de cobre, o con sal de oxitetraciclina (Júnior et al., 2005).

Costa et al., (2006), en un trabajo realizado a nivel de campo utilizando casugamicina e hidróxido de cobre para el control de A. avenae subps. citrulli, en melón, el tratamiento 2 (casugamicina $400 \mathrm{~mL} / 100 \mathrm{~L}^{-1}$ ) presentó el mayor valor porcentual $(86.66 \%)$ en términos de eficiencia de control: también no fue observado ningún efecto fitotóxico en las plantas de melón, igualmente no existió efecto sinérgico entre los defensivos estudiados. Se recomienda la utilización de casugamicina en una dosis de $400 \mathrm{~mL}$ de producto comercial para $100 \mathrm{~L}$ de agua para el control de la mancha acuosa en melón.

Silva et al., (2002), evaluaron la eficiencia de Acibenzolar-S-Metílico como inductor de resistencia al ataque de $A$. avenae subsp. citrulli (Aac) en la época lluviosa, en plantas de melón tipo Pele de Sapo cv. Sancho, en campos de producción de melón en el estado de Río Grande del Norte. La eficiencia de este ingrediente activo quedó comprobada en ese ensayo, el cual fue realizado en el período mencionado. El ingrediente activo 
Acibenzolar-S-Metílico se presentó como una excelente alternativa para el control de $A$. avenae subsp. citrulli, teniendo en cuenta los valores obtenidos en términos de productividad y gastos con las aplicaciones. Cabe destacar que este ingrediente no actúa directamente contra el fitopatógeno, más sí en la planta activando sus mecanismos de defensa.

Resultados obtenidos por Oliveira et al., (2006), demostraron que los antagonistas utilizados en su investigación (bacterias epifíticas y endofíticas y fungos endofíticos), tienen potencial como agentes de biocontrol de la mancha-acuosa en melón. También, el tratamiento de semillas es de gran potencial por ser un método práctico y simple en el control de esta enfermedad importante para los productores debido a las pérdidas que causa.

\section{Control fisico}

El pre - enfriamiento al cual son sometidos los frutos de melón para exportación, con el objetivo de bajar la temperatura de 10 a $15{ }^{\circ} \mathrm{C}$, es una medida de control eficiente para la mancha acuosa en la fase pos cosecha. Con todo, en el mercado interno, tanto en Río Grande del Norte como en otros estados del Noroeste y otras regiones, el transporte en camiones sin refrigeración y la comercialización en idénticas condiciones en supermercados y/o ferias libres favorecen la incidencia de la enfermedad (Silveira, 2003).

\section{LiTERATURA CITADA}

Andriguetto, J. R. y A. K. Kososki. 2003. Alavanca para exportação. Revista Cultivar Hortaliças e Frutas. 4:19.

Araújo, D. V., R. L. R. Mariano y S. J. Michereff. 2005. Métodos de inoculação de Acidovorax avenae subsp. citrulli em melão. Summa Phytopathologica. 31:72.

Assis, S. M. P., R. L. R. Mariano, D. M. W. Silva-Hanlin y V. Duarte. 1999. Mancha-aquosa do melão causada por Acidovorax avenae subsp. citrulli, no estado do Rio Grande do Norte. Fitopatologia Brasileira. 24:191.

Bezerra, A. C. de O. 2002. Eficiência de produtos bactericidas no controle da mancha-aquosa do melão: cv. Frevo. Mossoró-RN. Tesis presentada para la obtención de Ingeniero Agrónomo. Escola Superior de Agricultura de Mossoró-ESAM. Brasil.

Costa, F. M., R. S. Júnior, F. A. Almeida y M. V. Lopes. 2006. Eficiência de kasugamicina e hidróxido de cobre no controle da bactéria Acidovorax avenae subps. citrulli, agente causal da "Mancha-Aquosa" no meloeiro. Revista de Biologia e Ciencias da
Terra. 6 (1):132.

Hopkins, D. L., J. D. Cucuzza y J. C. Waterwon. 1996. Wet seed treatments for the control of bacterial fruit blotch of watermelon. Plant Disease. 80:529.

Hopkins, D. L., T. Kucharek, D. Gay, R. Gitaitis, W. Cook y A. Keinath. 1992. Bacterial fruit blotch of watermelon. Florida. American Sunmelon. Boletín.

Hopkins, D. L., C. M. Thompson, J. Hilgren y B. Lovic. 2003. Wet seed treatment with Peroxyacetic Acid for the control of bacterial fruit blotch and other seedborne diseases of watermelon. Plant Disease. 87:1495.

Isakeit, T., M. C. Black, L. W. Barnes y J.B. Jones. 1997. First report of infection of honeydew with Acidovorax avenae subsp. citrulli. Plant Disease. 81:694.

Júnior, S. R., I. S. Oliveira, R. L. R. Mariano, G. F. Silva y G. H. S. Nunes. 2005. Efeito de kasugamicina e oxicloreto de cobre no controle da mancha aquosa do meloeiro. Fitopatologia Brasileira. 30: 298.

Lopes, C. 2001. Controle de Doencas Bacterianas (Mesa redonda). Controles químico e culturais de Bacterioses de plantas. (CNPH/Embrapa). Fitopatologia Brasileira (suplemento). 26:264 (Resumen).

Mariano, R. L. R., E. B. Silveira, S. M. P. Assis, A. M. A. Gomes, I. S. Oliveira y A. R. P. Nascimento. 2001. Diagnose e manejo de fitobacterioses de importância no nordeste brasileiro. En: Michereff, S. J. y Barros, R. Proteção de Plantas na Agricultura Sustentável. Recife: Impressão UniversitáriaUFRPE.

Maude, R.B. 1996. Seedborne Disease and Their Control - Principles and Practice. Oxon: CAB International.

Michereff, S. J. y R. Barros. Proteção de Plantas na Agricultura Sustentável. Recife: Impressão Universitária-UFRPE.

Morrison, R. H. 1999. Sampling for decision making in crop loss assessment and pest management. Phytopathology. 89:1084. (Symposium).

Nascimento, A. R. P., R. L. R. Mariano y E. I. Silva. 2004. Hospedeiros alternativos de Acidovorax avenae subsp. citrulli. Horticultura Brasileira, Brasília. 22(3):514.

Oliveira, A., M. H. M. Santos, E. B. Silveira, A. Gomes y R. L. R. Mariano. 2006. Biocontrole da manchaaquosa do melão pelo tratamento de sementes com bactérias epifíticas e endofíticas. Horticultura Brasileira. 24:377.

Oliveira, I. S., R. S. Júnior y R. L. R. Mariano. 2003. Ocorrência da Mancha - Aquosa causada por Acidovorax avenae subsp. citrulli, em Melão - Pepino no Brasil. Fitopatologia Brasileira. 28(6):02111. 
(Nota Fitopatológica).

Pinto, F. M. V., A. S. Apoliano, R. J. Sales, J. C. Emilson y F. C. F. Oliveira. 2002. Monitoramento de Doenças na Produção Integrada do Meloeiro. EMBRAPA- Agroindústria Tropical, Fortaleza. Manual técnico (1a edição).

Robbs, C. F., N. J. Rodrigues y L. O. S. Berian. 1992. Podridões de frutos de melão em pós-colheita causadas por bactérias no Brasil. Fitopatologia Brasileira, Brasília. 17(2):195.

Sales, J. R. y J. B. Menezes. 2001. Mapeamento das Doenças Fúngicas, Bacterianas e Viróticas do Cultivo do Melão no Estado do RN. Mossoró: Escola Superior de Agricultura de Mossoró. (Relatório Técnico).

Santos, E. R., E. R. Gouveia, R. L. R. Mariano y A. M. Souto-Maior. 2006. Controle biológico da mancha-aquosa do melão por compostos bioativos produzidos por Bacillus spp. Summa Phytopathologica. 32(4):376.

Silva, E. I., R. L. R. Mariano, S. J. Michereff, R. J. Sales y I. S. Oliveira. 2003. Levantamento da incidência da mancha-aquosa do melão no Rio Grande do Norte e determinação do tamanho das amostras para quantificação da doença. Summa Phytopathologica. 29:174.

Silva-Neto, E. B., E. B. Silveira, R. L. R. Mariano, N. L. Nogueira, M. L. Rossi y L. A. Santos. 2006. Penetração e colonização de Acidovorax avenae subsp. citrulli em folhas, frutos e sementes de melão Amarelo. Fitopatologia Brasileira. 31:84.

Silva, E. I., R. J. Sales, P. Maracajá, G. Silva, F. Costa y R. Muniz. 2002. Utilização de indutor de resistência à mancha-aquosa em plantas de meloeiro. Caatinga, Mossoró-RN. 15(1/2):39.
Silva, V. A. V., E. B. Silveira y R. L. R. Mariano. 2006. Sobrevivência de Acidovorax avenae subsp. citrulli em meloeiro. Fitopatologia Brasileira. 31:384.

Silveira, E. B., S. J. Michereff y R. L. R. Mariano. 2003. Severidade da mancha-aquosa em meloeiro sob diferentes condições de molhamento foliar e concentração de inóculo de Acidovorax avenae subsp. citrulli. Fitopatologia Brasileira 28:171-175.

Silveira, E. B., R. L. R. Mariano, S. J. Michereff, y S. M. A. Oliveira. 2004. Influência da temperatura, umidade, concentração de inóculo de Acidovorax avenae subsp. citrulli e idade do fruto no desenvolvimento da mancha-aquosa em melão. Fitopatologia Brasileira 29(1):36.

Walcott, R. R., D. B. Langston, R. D. Gitaitis, D. Gay, D. L. Hopkins, T. A. Kucharek, R. Latin, D. Eggel, W. P. Cook, A.P. Keinath y B. Lovic. 2001. Guidelines for managing bacterial fruit blotch disease. Geórgia. Disponible en: < http://www.stalals.com/ flyer.htm >. Acceso en: 20 de abril del 2009.

Walcott, R. R., D. B. Langston, Jr. F. H. Sanders y R. D. Gitaitis. 2000. Natural Outbreak of a Bacterial Fruit Rot of Cantaloupe in Georgia caused by $\mathrm{Aci}$ dovorax avenae subsp. citrulli. Plant Disease. p. 372. (Abstract).

Wall, G. C. y V. M. A. Santos. 1988. New bacterial disease of watermelon in the Mariana Islands. Phytopathology. 78:1605. (Abstract).

Zitter, T. A., D. L. Hopkins y C. E. Thomas. 1996. Compendium of Cucurbit Diseases. St. Paul, Minnesota: Amarican Phytopathological Society. 